\author{
James Bradley \& Susan Bradley Smith
}

\title{
Royal ambitions: Creative writing and the Secret Rules of Courtship in the Medical Humanities
}

\begin{abstract}
Recent years have the seen the call for a melding of the humanities with biomedicine in the quasi-discipline of the medical humanities. The forging of such partnerships offers authority, status and utility for disciplines like creative writing. We will argue, however, for caution. We identify two different strands within the medical humanities: the critical and the paramedical. The first strand requires disciplinary autonomy to carry out its task effectively. The second strand, however, often becomes subservient to biomedicine, assetstripped for what is useful. We describe two case studies in the paramedical humanities where this process has occurred: the 'Creative Writing and General Practitioner Wellbeing' project, which used reflective writing to augment professional medical training and practice, with a view to enhancing GP wellbeing; and a description of a literature workshop facilitated by a medical practitioner for a medical humanities retreat in the United Kingdom. We argue that the problems identified are inherent to the paramedical humanities, a product, no less, of the history of biomedicine. Finally, we conclude that biomedicine needs the humanities, but not the medical humanities. Creative writing and other humanities disciplines should maintain their autonomy and, therefore, their integrity.

Keywords: Medical humanities; creative writing; narrative therapy
\end{abstract}

\section{Introduction - 'A Very Long Wake': Medical Humanities and the Two Cultures}

The Arts and Sciences have long held ambitions, often unrealised, for productive partnerships; at times, even royal ambitions. In her novel The Autograph Man, dedicated to taking the zeitgeist of twenty-first century London, Zadie Smith reminds us that 'On the magnificent mosaic that wraps itself around [London's] Albert Hall the following is engraved':

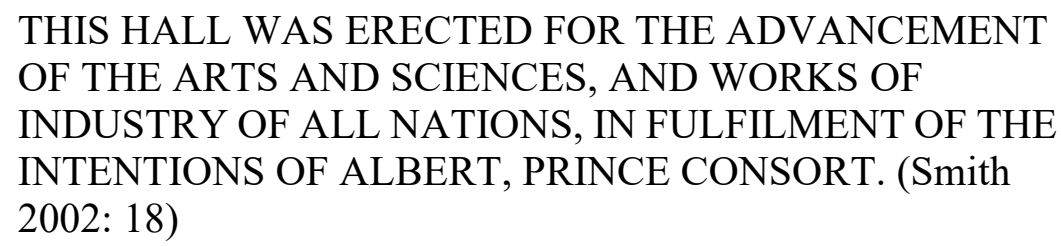

Queen Victoria's beloved Albert was long dead by the time she opened the hall in 1871, but Smith asks us to imagine the Queen as sometimes touring the hall 
alone, 'thinking of her dead husband and the fulfilment of his intentions'. Smith also suggests that, if one felt like it, one could possibly 'date the current pliancy of the phrase "Arts and Sciences" to the inauguration of Victoria's Albert Hall', arguing that:

Arts and Sciences did at one point mean Painting and Stuff and Petri Dishes and Stuff. It was a quite specific, stiff phrase and there wasn't a lot of room in it. The Albert Hall (one could argue, if one had a mind to) helped change that. (Smith 2002: 18-19)

Smith's vehicle for these observations was a sad father with a terminal illness and his son, off to witness a wrestling match in the Albert Hall - both 'smart enough to note the incongruity between these massive engraved words - ARTS AND SCIENCES - and what they are about to see' (19). But, Smith assures us, they remained 'jittery with anticipation' as they walked beneath the arch, 'about to take part in the latest episode of a very long wake' (21).

'A very long wake' - a taut and powerful phrase - summarises a fraught relationship, spanning the best part of two centuries. Smith's characters, however, read Albert's 'Arts' dialogically and therefore anachronistically. While the meaning of 'Arts' in the mid-nineteenth was not exclusive to acts of artistic creativity, encompassing the making of things as well as the praxis of science and medicine, her protagonists have very real cause to interpret the Hall's inscription as, at best, a forlorn hope. For in the early twenty-first century, it is clear that there remains the perception of a deep divide between what Snow (1959) famously called the 'Two Cultures'. Not only that, but an older hierarchy appears to have been upended. When, in the 1880s, Matthew Arnold argued with TH Huxley the relative merits of the liberal arts over the sciences, he was able to hold his ground, and might even have been judged to have bested Darwin's bulldog (White 2003: 81-94). There can be little doubt that today, in higher education and beyond, the sciences are privileged over the arts - their relative position self-evident in a society where impact is measured in terms of contribution to economic growth. It is unsurprising that we, as researchers and teachers in the humanities, are inveigled into forging industry links, engaging in inter-disciplinary projects, and justifying our teaching in terms of generic skills that can be sold to potential employers. We are assured that these are ways in which we can make the humanities relevant (something most scientific disciplines do not have to do) and counter the charge that a Bachelor of Arts is, as one commentator sourly noted, nothing more than 'welfare in reverse' (Roskam 2014).

It is in this culture, where the humanities are being, for want of a better word, utilitarianised, that hybrid disciplines have emerged that seek to imbue them with 'relevance' and 'value' by enfolding them within the sciences. The medical humanities is one such discipline - or disciplines, depending upon whether you regard it as inter-disciplinary or multi-disciplinary project (Bates \& Goodman: 2014: 4). The star of the medical humanities has been in the ascendant since at least the 1990s (Dolan 2010). And yet, at the same time, it suffers from a chronic insecurity driven by its sheer amorphousness. Bleakley is only the most recent to observe that the medical humanities consists of several streams that do not necessarily communicate with each other, almost as if they are tributaries without a river (Bleakley 2014: 17). These range from critiques of biomedicine by historians, anthropologists, sociologists, cultural studies practitioners and literary critics, to a paramedical practice where the various disciplines of the humanities become the bondservants of biomedicine. In the increasingly neo-liberal market place that is rapidly transforming higher education and biomedicine, many are drawn towards the medical humanities as 
a paramedical practice, because it appears it might generate value. At the same time, the actual use-value remains hard to quantify and lacks an evidence base - that most desirable of qualities for contemporary biomedicine. While it is relatively easy to quantify the value of screening or the profits of a particular pharmaceutical product, the same cannot be said of humanities-led interventions in biomedicine; a situation which often leads the paramedical practitioners of the medical humanities to feel 'beleaguered and diminished by the demands to calculate the value' of what they do (Jones 2014: 28).

It is this tension between critique and utilitarianism that is the focus of this essay. Here we will explore the syncretic discipline of the medical humanities from the perspective of our personal experience of encounters between the humanities and medicine, which have resolutely been in the paramedical zone of encounter. In particular, we will present two case studies where writing and literature were used as tools to 'humanise' medicine and medical practitioners. The first of these case studies was a project designed to foster well being among hard-pressed and over-stressed medical practitioners, designed and implemented by Bradley Smith in partnership with a general practitioner. The second explores a medical humanities' workshop attended by Bradley Smith in the United Kingdom, which attempted to use canonical literary texts to provide insights into the nature of medicine, illness and the business of doctoring. We will suggest that both projects, with their avowed royal ambitions of melding medicine and the arts, are typical of the contemporary thrust of the paramedical humanities. But such a project possesses inherent flaws, in particular the failure of the reflective writing model to account for the historically determined nature of biomedicine and the patient-practitioner relationship. In carrying out this critique, we will not imply that there should be no dialogue between the humanities and medicine; rather that we should exercise caution in assuming that the humanities, especially creative writing and literary criticism, possess the major paramedical function that has been ascribed to them: the notion that narrative skills combined with the moral lessons of great literature can humanise science-blinkered medical students and practitioners creating a better biomedicine (Gordon 2005, 2008; Charon 2006).

\section{Writing and reading doctors: Two case studies in the Paramedical Humanities}

Recovering from severe depression, which included a period of being unable to read or write, part of Bradley Smith's recovery involved the completion of a collection of poems (Bradley Smith 2006). Once well, the GP who had treated her through her illness asked to read the poems (subsequent, of course, to the termination of their doctor-patient relationship). One was rather uncomplimentary; it reflected upon his suggestion that Electroconvulsive Therapy (ECT) was a genuine therapeutic option. When the GP read this poem, he was 'inspired', or perhaps goaded, to write one 'back', the first he had written since primary school. Thus began a creative and research relationship.

The GP, also a senior medical educator at an award-winning provider of GP training, was intrigued about the effects of his creative act - this process of getting something off your chest by writing it down. And, indeed, it has long been recognised that the process of creating a narrative, in whatever form, can have therapeutic benefits. Almost the entire edifice of psychotherapy is based upon this premise, irrespective of the particular theory or school from which its variants derive. Get to the place of trauma, understand the trauma, and reset (perhaps, by rewriting) the narrative of your life in the light of this new selfknowledge. This was the impetus of Freudianism and its off-shoots, which 
dominated the psychiatric landscape for much of the twentieth century. There was something of it in the various forms of art therapy deployed by psychiatry post-World War 2. It underwrote the rationale of the radical anti-psychiatrists, including RD Laing and David Cooper, with their bent for Sartre and existentialism (Cooper \& Laing 1964). It remains the goal of many counsellors and psychologists in contemporary practice (here the trauma-model remains, largely shorn of its Freudian base). It is what drives those aspects of the medical humanities that focus upon reflective writing as a beneficial means of restructuring or reordering one's life. And it most definitely forms the bedrock of Charon's (2006) 'Narrative Medicine' programme, a quasi-discipline that aims at nothing less than the wholesale transformation of medical practice through the use of narrative techniques.

With the evident potential of narrative to sort things out, at the GP's suggestion, Bradley Smith and the doctor decided to co-write a play about the doctorpatient relationship, exploring, in particular, the doctor's feelings. It was a cooperative venture that soon expanded. A research partnership between his GP training organisation and Bradley Smith was established. Funds were secured for a pilot project, and the 'Beyond the Medical Record: Creative Writing for Doctors' workshop programme was formulated. The guiding rationale of the workshops was that which had been elaborated by key medical humanities' theorists, particularly Bolton (2005) and Gordon (2005), who in turn had influenced Charon in the development of Narrative Medicine. In particular, the programme was influenced by the notion that narrative techniques might reset the reality of hard-pressed GPs in beneficial ways, alongside the belief that the desire to 'be of interest' to oneself is an essential component of wellbeing. The intention was not to offer 'consolation' or insist on writing as a therapeutic tool, but to focus on creative explorations of what it meant to be a GP, and to estimate the value of creativity and reflexivity to wellbeing. The programme was conducted during 2006, along with other arts and medicine initiatives.[1]

But would it work in practice? Can creative and reflective writing reset reality, or at least tamper with it? According to the social anthropologist Claude LéviStrauss, the tales that a society invents and mythologizes are similar to mathematical structures, in that they seek to solve contradictions. He argues that stories and 'mythical thought always progresses from the awareness of oppositions toward their resolution'. That is, myths consist of elements that oppose or contradict each other, and as the narrative of the story progresses, bothersome contradictions are mediated (Lévi-Strauss 1963: 224). If it is true that storytelling and mythmaking - vital components of creative thinking - can solve problems, then the GPs who attended these writing workshops, were, for that time at the very least, 'of interest' to themselves. Less 'contradicted'. Happier.

Doctors write about anything and everything, and literary history is well populated with examples of the doctor-writer. The workshops, however, with their focus on reflective writing - which by its very nature concentrates on selfexploration - had a more defined outline and a less ambitious one than creating literary masterpieces, or producing career-writers. Although an exercise might have begun, for example, with the challenge to write a poem pretending that you are a disease, the final draft of that poem could easily be about guilt, or love, or any emotion that might surface during the reflective process.

Each workshop had a distinct theme. The first, 'Once upon a time: Medicine, literature and writing', explored the role of stories in the doctor-patient relationship; the role of language in clinical practice; and stories of doctors' experiences, as well as the effect their work has upon their lives. The second, 
'And they all lived happily ever after: Writing for personal and professional development', enabled participants to explore the use of creative writing as a prophylactic for professional burn-out; the potential that reflective writing possesses for revealing the impact of work on a doctor's wellbeing; and the use of creative writing as tool for improving communication skills within the doctor-patient relationship. The stated objectives of this program were: to assist in a greater understanding of what it means to be a doctor; to enhance participants' creative writing skills; and to improve participants' professional and personal wellbeing.

So what did the participants think? In general, formal evaluations reveal that the respondents were highly satisfied. Of particular note was the amount of praise for the workshop facilitation which combined not only a writer and a doctor, but did so in the form of two individuals who had been frank and revealing about their own selves, whilst prefacing the workshops, during the warm-up discussions, with a history of their collaboration (which involved revealing their own frailties). Several themes, or effects, were revealed by the feedback. Participants noted, for example, that certain (unbidden) needs surfaced through their writing, including 'the urge to tell one's story' ('There are incredible stories we want to record and are not able to do justice to'), and, 'writing our pain' to enhance wellbeing: 'We know there are a lot of miserable doctors. Burnt out', commented one participant. 'We talk a lot about ways you can manage, like doing less work. That is not a solution. We need to find ways to enjoy the work. Courses like this might help you get out of it what you said you wanted from it (the profession) in the beginning.'

Furthermore, writing about significantly harrowing or vexing events and situations in which they found themselves was oft mentioned. Comments ranged from 'today I wrote about something I was angry about ... [writing] can help doctors to cope', to 'I will suffocate unless I do something creative in my life'. But allied with this notion that creative writing might function as a release, was the expressed belief of some participants that the act of writing would help to find new meaning in daily practice, with its manifold complexities. Significantly, one participant reflected, some six weeks later, that:

The workshop seems to have given me a fresh look on my profession. I feel a bit less isolated with concerns that I sometimes have. It is a great opportunity to share ideas and feelings among colleagues. This usually does not happen between fellow doctors as we are too busy in our jobs. We also do not want to bother each other on the assumption that the colleague might not be responsive to that issue or that we might stir up some personal issues, he/she might have. [2]

It was generally agreed that the workshops provided a 'wonderful chance to share experiences with your colleagues' in an open, frank and non-judgmental forum. Most agreed that the focus on 'doctoring' was a key ingredient of the workshops' success: 'being a doctor is inhibiting - you can't talk about it. The general public has a different experience than we do. This gave me a chance to do a workshop where we share common experiences among doctors'.

Certain societies, in particular regional Australian ones, cannot afford to lose their doctors. Professional attrition is a real problem. And the workshop programme appeared to offer a tool for combatting what has become a serious problem in rural Australia, which was recognised when the programme went on to win an Australian General Practice Education and Training award for innovation later that year (http://www.ncgpt.org.au/awards). Given the success 
of the programme, it would be tempting to extrapolate a bright future for similar collaborations.

For many reasons, some illustrated above, we might celebrate and advocate this marriage of the disciplines. Yet this should not prevent our questioning the integrity of the relationship between the humanities and biomedicine, particularly the seemingly inevitable deficit of power that will be involved in the process. The following story serves as a parable.

Bradley Smith attended a two-day Medical Humanities retreat in England some years ago, attended by medicos from all over Europe. They were a gifted, dedicated and hard-working bunch. There was, as well, a minority of delegates, perhaps as little as ten per cent, who were artists and writers working in healthcare settings. The retreat's express purpose was to explore the illumination of medical practice by the humanities. Workshops ranged from art therapy to dramatic play, and literary criticism to film studies. As an accredited retreat, medical practitioners could earn their compulsory professional development points, but there is much competition for such business, so something more than compulsion lay behind their choice to attend. Most were there to expose themselves to the humanities, either to gain new insights into their professional practice, or simply to garner intellectual pleasure. As a practitioner of the medical humanities, Bradley Smith was there to see more of the world in which she had chosen to operate. But she was also attended as a teacher whose aim was to witness how the medical humanities were being peddled and what quality controls were in place to ensure effective pedagogy.

Unfortunately some conduct verged on the scandalous. The literature workshops were a case in point. A lengthy discussion was held about a series of set texts where a doctor was the protagonist, with the express aim of exploring the doctor as literary subject through time. The pre-reading schedule had been large, heavy and predictable. The facilitation was more in the style of a nineteenth-century lecture than a seminar or workshop. Many of the doctor participants had insightful observations about the texts in their historical and sociological contexts. All were genuinely involved in the quest to locate meaning and to apply this to their own contexts. But eventually, the facilitator squarely told the group what the text really meant - discussion terminated and debate silenced.

A number of the participants were left feeling confused, and towards the end of the workshop one of these who knew Bradley Smith's core business asked her opinion. It was a controversial moment. She replied that in her experience literary theory had moved beyond the insistence upon a singularity of meaning. Oh. Really? Then what do you think the writer meant in this instance? She responded with a short summary of what a variety of literary interpretations of the texts might offer from the psychoanalytical to the postcolonial. Everyone started talking at once; having been temporarily freed from the boredom that transmission-modelled pedagogy often generates the group was, for the first time, animated. Then the facilitator intervened. Yes. Of Course. But that's not really what the author meant and so none of that is useful at all. Is it?

It seems that some doctors think that they can 'do' our jobs. After all, how skilled do you have to be to read a book, discuss it, and then settle upon a meaning? This presumption, quite sensibly, is a one-way street. Margaret Atwood, whose own grandfather was the kind of doctor who drove sleighs through blizzards to deliver babies on kitchen tables, famously related an anecdotal exchange between herself and a surgeon at a cocktail party. I've always wanted to write a book, he said. I think I might try one this summer, to which she responded that over the summer holidays she herself was planning to 
do a bit of brain surgery. She put it more pointedly in Negotiating With the Dead: 'everyone can dig a hole in a graveyard, but not everyone is a gravedigger' (Atwood 2003: 23). Most people, even if they can dig a hole with their own shovels, don't really understand the specialised crafts and skills of the occupation: the special and necessary relationship to soil; the architecture of digging deep and straight, or the reverence for funerary customs and the world of the dead.

\section{Narrative medicine, creative writing and the history of medicine}

This is not to say that all encounters between biomedicine and the humanities are doomed to this outcome. Rather that there are secret rules of courtship that create an inherent danger in the medical humanities, particularly the paramedical humanities, that inherently lead to the colonisation of the humanities by biomedicine. Here we explore how these rules have come to be. For the problems at the heart of the alliance are more intractable than might at first be apparent. We start with an analysis of Charon's Narrative Medicine (2006) and the centrality she gives to the role that it should play in humanising biomedical practice and practitioners. What we offer, then, is a tentative genealogy (in the Foucauldian sense) of her programme.

Charon insists that narrative lies at the heart of the experience of sickness. Patients have narratives, doctors have narratives, and often these narratives are very different, even diametrically opposed. For her, the doctor's narrative is reductive and overly scientific. The patient becomes a cluster of symptoms and the bearer of the signs of a particular disease or syndrome, but their whole person, including their own stories of illness, are ignored. Teach the doctor to understand the patient's narrative and a previously dehumanised biomedicine will fulfil its potential to soothe the soul, even when it cannot cure the body. To this end, she demands that all health professionals be trained in narrative techniques, which once learned will allow them to unpack the experiences and feelings of their patients. Narrative medicine properly practised, would inevitably involve creative writing as partner. So far it sounds not dissimilar to Bolton (1999), who has argued for the therapeutic potential of creative writing. But Charon is far more ambitious. In her hands narrative medicine does not simply support therapy, it utterly transforms biomedicine, root and branch, making it patient-centred and empathetic. She makes a huge promise, which at the very least ought to be enticing for creative writing professionals. For it carves out a space that neatly fits the neo-liberal university's mission to maximise value, even in disciplines where value cannot be accounted. But it is a promise that is built upon a naïve reading of the history of biomedicine. It is to this history that we turn to elicit the limitations of the paramedical humanities founded upon narrative theory and practice, ultimately questioning whether such a project is feasible in the first place.

Charon's version of the medical humanities arose out a revolt against the perceived excesses of the medical profession, in particular its tendency towards scientific reductionism. To understand this, we need to know something about the history of biomedicine. The story we are about to tell has long been in the making, finding its roots in, among other places Ackerknecht's Medicine at the Paris Hospital (1967) and Foucault's Canguilhem-inspired (1943) Birth of the Clinic (1973). Before the 1800s, disease was configured within an holistic framework: a person became sick due to an imbalance in their body that might have been created by any number of social or environmental factors, including poor diet, not enough sleep, and too much stress. It was the medical practitioner's job to understand the patient's personality and circumstances, and 
then use a variety of techniques to restore the body to balance. It was a world where patient and practitioner shared the same understanding of disease and spoke about it in the same language.

A major transformation occurred, however, during the second half of the eighteenth century that found its epitome in the Paris hospitals during the revolutionary years at the end of the century (Maulitz 1987). Increasingly disease became understood as a physical event occurring in specific tissues or organs. The development of anatomy and pathology led to a new regime where detailed case histories were taken from patients while they lived, which were then correlated with symptoms found in the body after the patient had died. The post-mortem became critical to identifying and understanding the progress of disease, while nosology was reconfigured - the map of disease redrawn (or reduced) to localised events occurring in particular parts of the body. Disease was no longer a general state of imbalance but a specific state reduced to an individual body part or parts. From henceforth, it was claimed, medicine ceased to regard the patient as an individual, but as the bearer of diseased organs or tissues. The process was completed with the advent of the germ theory of disease and, the emergence of laboratory medicine, as it was called, in the midto-late nineteenth century. Now it was disease at the cellular level that became the main focus for the scientific medical practitioner.

Of course, this model was drastically over-stated. Right the way through the nineteenth century, even after the emergence of germ theory, the causes of disease were still often configured within holistic terms, with the patient's body threatened by their lifestyle and their environment. There was never a time when the medical practitioner could wholly discount the life circumstances of their patient, or understand them as being less than a whole. In reality the patient never disappeared, but there is no doubt that the vast majority felt that medical science had become increasingly dehumanised.

Certainly, by the end of 1960s, biomedicine, which on the face of it had never been so effective, had also never been so unpopular. Much of this was due to the social and cultural revolt against the old order, a challenge that arose in part from academia itself. University-based scholars became activists, whose work was geared to revealing the corrupt and dehumanising power of capitalism. Amongst the many political and social institutions found guilty of perpetuating alienation, medicine, for so long perceived as a force for good in society, now took its place in the firing line, alongside big business and liberal democracy. The talk was of the 'medicalization of life' itself (Illich 1975).

The radical critique put many witnesses on the stand. To be sure, medicine had brought the wonders of vaccination and antibiotics to the people, obliterating killer diseases and infections with the simple administration of serums and pills. At the same time, it had seemed to preside over horrific abuses. It was not simply the Nuremberg revelations of the inhumane behaviour by Nazi scientists (Weindling 2004), or the unmasking of the Tuskegee experiment conducted unwittingly on a group of African-American men between 1932 and 1972 (Reverby 2009). Neither was it a simple knee-jerk reaction to the horrors of thalidomide (Brynner \& Stephens 2001), nor the succour medicine had offered to the established hierarchies of race (Dittmer 2009) and gender (Chesler 1970; Greer 1970; Ehrenreich \& English 1973). Neither was it solely a response to the undermining of biomedicine's status by the controversial but influential McKeown thesis (see, for example, McKeown 1976), which appeared to suggest that economic growth rather than medicine had been responsible for the general improvement of health among western populations. Nor even could it be reduced to the radical critiques of professional power, which suggested that the development of the medical profession had been motivated by the self- 
interested desire for higher social status, rather than the individual or collective humanitarianism of doctors (Freidson 1970; Johnson 1972). Rather, it combined all of these strands into a story of how medicine had dehumanised the patient, effectively alienating her from her own experience of illness.

These concerns emerged in a variety of places, including anti-psychiatry (Crossley 1998) and the Radical Science Movement (Werskey 2007). But these responses to the evils of biomedicine coalesced in Illich's pamphlet Medical Nemesis (1974b), which not only accused medicine of being ineffective in the face of disease, but also suggested that most disease was iatrogenic, created by the monstrous powers of medicine. But it was not just biomedicine's capacity to create disease that concerned Illich; it was also its ability to expropriate the experience of illness from the patient, a critique that found its way into Jewson's sick-man thesis (1976).

Some medical practitioners took Illich's assault upon biomedicine very seriously, particularly after his thesis was abstracted in a Lancet article (Illich 1974a). They were not only concerned about biomedicine's reputation, but also the extent to which it had become implicated in human suffering (Bradshaw 1974; Discombe 1974; Mitchell-Fox 1974; Smith 1974; Keeve 1974). Of course the majority defended the role of science in medicine, insisting that progress could only come on the back of detailed scientific research, which by its very nature was reductive. In fact, more and better science was the prescription laid down for the effective reform of medicine: the problem was not that medicine had become too scientific, but that it was not scientific enough (and looking at how, for example, thalidomide had failed tens of thousands of people, this was a difficult point with which to argue). It is, therefore, no coincidence that Evidence Based Medicine emerged as force during the 1970s, the Cochrane Institute having set up for business in Oxford in the first year of that decade (Daly 2005).

Neither was it a coincidence that the biopsychosocial model was proposed with some fanfare in 1977 (Engel 1977). Its author, George Engel had had a longstanding interest in the connections between mind and body in sickness and in health. His unequivocally titled 'The Need for a New Medical Model: A Challenge for Biomedicine' launched the model. By bridging the worlds of physician and psychiatrist, Engel was perfectly placed to understand the strengths and weaknesses of the biomedical model of disease, and he addressed himself to the perceived failings of psychiatry, which appeared to have been singularly unsuccessful in developing a suitably scientific aetiology.

No doubt fresh in the minds of both Engel (1977) and his audience was Rosenhan's (1973) devastating paper, 'On Being Sane in Insane Places', which had revealed psychiatry's inability to diagnose scientifically. And yet, while the conference-goers were anxious about psychiatry's status within biomedicine, Engel was concerned with the fact that biomedicine itself was suffering exactly the same problems: 'namely, adherence to a model of disease no longer adequate for scientific tasks and social responsibilities' (129). The inherent scientific reduction of biomedicine, he argued, had signally failed to meet the needs of the patient - a new holistic approach was required, represented by his model, which would transform medical education in a way that would make future doctors consider the social and emotional contexts of the patients when treating their illnesses. In this way the patient would be reintegrated into medical cosmology as a complete individual, safe from the worst aspects of medical reductionism. And so it came to pass - now there is not a medical school in Australia that does not predicate its teaching upon the biopsychosocial model. 
There can be little doubt that it was these combined forces, articulated as a general dissatisfaction with the reductionist nature of biomedicine, with its concomitant dehumanising tendencies, that catalysed the new field of medical humanities, which could then position itself as a handmaiden of the biopsychosocial revolution (Cole et al 2014: 9; Agnew 1977: 597). 'Medical Humanism', as the medical humanities was initially described, was to play a part in re-humanising trainee doctors, countering their science with a healthy dose of culture (Doran 1983). Reading the great works of literature, for example, might lead to greater insights into human nature and suffering than knowledge of pathological change at the cellular level.

However, the emergence of medical humanism was, in reality, the rebranding of quite an old project - perhaps as old as the great clinician William Osler's emphasis on the importance of history and culture to medical art (Bliss 1999: 499-500; Ghaemi 2010: 128-44). Indeed, since Osler, the history of medicine had been touted by medical educators as the best means of inculcating effective medical values into trainee doctors. For this reason, in the USA, many of the best medical schools had a history of medicine programme. By focusing on the biographical example set by the great men (and almost always they were men), medical students would gain an understanding of the qualities that went to make the best type of medical practitioner - a combination of sacrifice to the greater good, scientific acumen, in-built intuition, and a fundamental understanding of human nature (Cook 2010; Dolan 2010: 395-98). But the history of medicine had started to disappoint as a teacher of humanised medical values. A new generation of professionally-trained historians was replacing the older generation of medical men who had dominated the writing of medical history up until the 1970s. The new history, far from endorsing medicine as 'the greatest benefit to mankind', followed the lead provided by radicals like Illich. They were frequently critical of medicine and medical men. They sought to recover the lost voices of silenced patients, much in the way that EP Thompson had done for the English working class (Thompson 1963). Medical humanism, on the other hand, created a space for a depoliticised engagement between medicine and the humanities, where history or literature could revalidate medicine and medical practice, while providing a tool that would nicely educate future medical professionals in the woollier ways and wiles of the biopsychosocial model.

Charon appears oblivious to the historical development of modern biomedicine. Few if any historians are to be found in the pages of her monograph. She therefore abjectly fails to acknowledge that biomedicine, the biopsychosocial model, medical practitioners (physicians, surgeons), and even patients are contingent upon social and cultural forces that shape these institutions, practices and roles. Using the terms that Hacking (1999: 19-20) applied to the political intentions of social constructionists, Charon attempts to unmask the problems within biomedicine but is merely reformatory in her intentions. She is neither rebellious, nor revolutionary. She sees things that have gone right (including the improved effectiveness of therapy), as well as the things that have gone wrong (the reliance upon science eclipsing the patient's experience of suffering) and must be put right. She aims to produce a better biomedicine. The solution to its ills is simple and lies in the adoption of a narrative approach to medical practice, whereby narrative techniques, including creative writing, will be used to allow self-reflection by the practitioner to enhance their ability to understand the patient's narrative and empathise with their plight.

Without knowing it Charon's critique of medicine might have emerged fully formed from a reading of Fissell (1991), which itself was the post-structural child of Jewson's structural 'sick-man' thesis (1976). Both Jewson and Fissell's arguments were themselves historically determined, produced in times and 
places that were conducive to their respective theoretical frameworks. The historical sociologist Armstrong has, however, pointed out that the patient is entirely contingent upon biomedicine - she is nothing less than its creation, formed within the interstices of biomedical power (Armstrong 1984; Condrau 2007). If the patient's narrative is silenced it is because biomedicine, in theory and in practice, demands it. The very word itself is semiotically charged to signify passivity and subordination. It is even possible, although controversial, that biomedicine works so well because silence, or at least a degree of subjugation, has been built into the role of patient. But one thing is certain; an active patient would no longer be a patient but something of an entirely different kind. From this perspective, narrative medicine could do little to change the reductive nature of biomedicine.

\section{Biomedicine and the Humanities together apart}

The historian of medicine Roger Cooter (2013: 43-44) has insisted that the vogue for interdisciplinarity has been driven by the neo-liberal policies of university administrators, who see in it the means of making the humanities useful to the dominant mode of production. Unsurprisingly, for Cooter, the medical humanities are fully complicit in this project. Cooter was defending disciplinarity as a concept, while insisting that in its encounters with medicine historiography should remain autonomous. There are, indeed, philosophical and conceptual problems with inter-disciplinarity that make the construction of a truly syncretic medical humanities unlikely, if not impossible. Disciplines have arisen for good reasons, built upon a shared set of methods and goals even research programmes - that evolve over time (Jones 2013; Post 2009). Even within the humanities the methods and goals between different disciplines may border upon the incommensurable. In this context, the 'royal ambitions' of the medical humanities are vitiated - the arts cannot and will not meet the biomedical sciences in the way envisaged either by Prince Albert or Smith's protagonists. We are then left with two multidisciplinary strands: the medical humanities as critique or as a paramedical practice. The disciplines involved in the critical strand of medical humanities require disciplinary autonomy. Only the independence of creative writing or history guarantees their ability to represent and describe the development of biomedicine without being beholden to it. The same is true of all disciplines within the ambit of the humanities, including newer configurations like cultural studies. In this model, the medical humanities disappear, replaced by different disciplines whose subject of study might be biomedicine.

The medical humanities as paramedical practice, on the other hand, runs the risk of being overwhelmed by biomedicine, which all too often assumes the role of 'senior' partner in the relationship. Colonisation was certainly the order of the day in the two case studies presented here. The qualified medical practitioner directing a workshop on the lessons of literature, who believes there is only one way to read a text and garner its moral lessons for medicine, may never have heard of Leavis (1960) but surely walks in his shadow. The 'Creative Writing' workshops designed and developed by Bradley Smith were subsequently taken over by a GP, and since that time have been facilitated by that individual (not unlike Atwood's putative novel-writing surgeon). While it might be argued that both case studies are unrepresentative, it is worth reflecting upon the dangers that are integral to the paramedical humanities, and which make possible the conditions for disciplinary colonisation. From the perspective of the biomedical practitioner, we see the belief that the humanities merely consist of a set of easily learned techniques to be applied only where useful in biomedical contexts. In this model the humanities will always remain 
subservient and asset-stripped for what is useful. On the other hand, as discussed above, the notion that biomedicine and its practitioners might somehow be metamorphosed by the humanising influence of literature and narrative is logically flawed because the success of biomedicine has been predicated upon the construction of a very specific kind of patient-practitioner relationship, which within biomedicine's own remit has been extraordinarily successful.

Biomedicine needs the humanities, but it does not need the medical humanities. It can, if it so chooses, listen to or adopt those critiques and strategies that are useful to it, incorporating them as it wishes within medical curricula and professional development. Nor does creative writing need the medical humanities. Nor indeed do any of the other disciplines that constitute the humanities. In fact, as this essay has attempted to demonstrate, autonomy should be prized and defended at all costs. Dialogue, discussion, dispute and dissent should form the terrain upon which the humanities and biomedicine encounter each other. This, above all else, should be our 'royal ambition': biomedicine and the arts, together apart.

\section{Notes}

[1] Additional writing workshops were conducted as part of the inaugural Association of Medical Humanities (Australia and New Zealand) conference, 'Taking Heart', held in Byron Bay, NSW, July 2006. return to text

[2] Private responses from workshop participants to the author, published with permission. return to text

\section{Works Cited}

Ackerknecht, EH 1967 Medicine at the Paris Hospital 1794-1848, Johns Hopkins Press, Baltimore return to text

Agnew, LRC 1977 'Humanism in Medicine', The Lancet 310, 8038 (17 September): 596-8 return to text

Armstrong, D 1984 'The Patient's View', Social Science \& Medicine 18, 9: 737-744 return to text

Atwood, M 2003 Negotiating with the Dead, Virago, London return to text

Bates, V \& S Goodman 2014 'Critical Conversations: Establishing Dialogue in the Medical Humanities', in V Bates, A Bleakley \& S Goodman (eds) Medicine, Health and the Arts: Approaches to the Medical Humanities, Routledge, London return to text

Bleakley, A 2014 'Towards a "Critical Medical Humanities", in V Bates, A Bleakley \& S Goodman (eds) Medicine, Health and the Arts: Approaches to the Medical Humanities, Routledge, London return to text

Bliss, W 1999 William Osler: A Life in Medicine, Oxford University Press, Oxford return to text

Bolton, G 1999 The Therapeutic Potential of Creative Writing: Writing Myself, Jessica Kingsley, London return to text

Bolton, G 2005 Reflective Practice: Writing and Professional Development, 2nd edn, Sage, London return to text 
Bradley Smith, S 2006 Marmalade Exile, Southern Cross University Press, Lismore return to text

Bradshaw S 1974 'Medical Nemesis', The Lancet 304, 7881 (14 September): 647-8 return to text

Brynner, R \& TD Stephens 2001 Dark Remedy: The Impact of Thalidomide and its Revival as a Vital Medicine, Basic Books, New York return to text

Canguilhem, G 1943 Essai sur quelques Problèmes Concernant le Normal et le Pathologique, Le Montagne, Clermont-Ferrand return to text

Charon, R 2006 Narrative Medicine: Honoring the Stories of Illness, Oxford University Press, Oxford return to text

Chesler, P 1970 Women and Madness, Doubleday, New York return to text

Cole, TR, NS Carlin \& RA Carson 2014 Medical Humanities: An Introduction, Cambridge University Press, Cambridge return to text

Condrau, F 2007, 'The Patient's View Meets the Clinical Gaze', Social History of Medicine 20, 3: $525-40$ return to text

Cook HJ 2010 'Borderlands: A Historian's Perspective on the Medical Humanities in the US and the UK', Medical Humanities 36, 1: 3-4 return to text

Cooper, D \& RD Laing 1964 Reason and Violence: A Decade of Sartre's Philosophy, Tavistock, London return to text

Cooter, R with C Stein 2013 Writing History in the Age of Biomedicine, Yale University Press, New Haven return to text

Crossley, N 1998 'R. D. Laing and the British Anti-psychiatry Movement: A Socio-historical Analysis', Social Science \& Medicine 47, 7: 877-89 return to text

Daly, J 2005 Evidence-based Medicine and the Search for a Science of Clinical Care, University of California Press, Berkeley CA return to text

Discombe, G 1974 'Medical Nemesis', The Lancet 304, 7880 (7 September): 584-5 return to text

Dittmer, J 2009 The Good Doctors: The Medical Committee for Human Rights and the Struggle for Social Justice in Health Care, Bloomsbury, New York return to text

Dolan, B 2010 'History, Medical Humanities and Medical Education', Social History of Medicine 23, 2: 393-405 return to text

Doran, GA 1983, 'Scientism vs Humanism in Medical Education', Social Science \& Medicine 17, 23: $1831-35$ return to text

Ehrenreich, B \& D English 1973 Complaints and Disorders: The Sexual Politics of Sickness, Feminist Press, Old Westbury NY return to text

Engel, GL 1977 'The Need for a New Medical Model: A Challenge for Biomedicine', Science 196, 4286: 129-36 return to text

Fissell, ME 1991 'Disappearance of the Patient's Narrative and the Invention of Hospital Medicine', in R French \& A Wear (eds) British Medicine in an Age of Reform, Routledge, London: 92-109 return to text

Foucault, M 1973 The Birth of the Clinic: An Archaeology of Medical Perception, trans. A Sheridan, Routledge, London return to text

Freidson, E 1970 Profession of Medicine: A Study of the Sociology of Applied Knowledge, University of Chicago Press, Chicago return to text 
Ghaemi, NS 2010 The Rise and Fall of the Biopsychosocial Model: Reconciling Art and Science in Psychiatry, Johns Hopkins University Press, Baltimore return to text

Gordon, J 2005 'Medical Humanities: To Cure Sometimes, to Relieve Often, to Comfort Always', Medical Journal of Australia 182, 1: 5-8 return to text

Gordon, J 2008 'Humanising Doctors; What Can the Medical Humanities Offer', Medical Journal of Australia 189, 8: 420-21 return to text

Greer, G 1970 The Female Eunuch, MacGibbon \& Kee, London return to text

Hacking, I 1999 The Social Construction of What? Harvard University Press, Cambridge MA return to text

Illich, I 1974a 'Medical Nemesis', The Lancet 303, 7863 (11 May): 918-21 return to text

Illich, I 1974b Medical Nemesis, Caldar \& Boyars, London return to text

Illich, I 1975 'The Medicalization of Life', Journal of Medical Ethics 1, 2: 73-77 return to text

Jewson, N 1976 'The Disappearance of the Sick Man from Medical Cosmology, 1770-1870', Sociology 10, 2: 225-44 return to text

Johnson, TJ 1972 Professions and Power, Macmillan, London return to text

Jones, JA 2013 In Defense of Disciplines: Interdisciplinarity and Specialization in the Research University, University of Chicago Press, Chicago return to text

Jones, T 2014 'Oh the Humanit(ies)! Dissent, Democracy and Danger', in V Bates, A Bleakley \& S Goodman (eds) Medicine, Health and the Arts: Approaches to the Medical Humanities, Routledge, London: 27-38 return to text

Keeve, JP 1974 'Medical Nemesis', The Lancet 303, 7867 (8 June): 1160 return to text

Leavis, FR 1960 The Great Tradition: George Eliot, Henry James, Joseph Conrad, Chatto \& Windus, London return to text

Lévi-Strauss, C 1963 Structural Anthropology, trans. C Jacobson, Basic Books, New York return to text

Maulitz, RC 1987 Morbid Appearances: The Anatomy of Pathology in the Early Nineteenth Century, Cambridge University Press, Cambridge return to text

McKeown, T 1976 The Role of Medicine: Dream, Mirage, or Nemesis? The Nuffield Provincial Hospitals Trust, London return to text

Mitchell-Fox, TM 1974 'Medical Nemesis', The Lancet 304, 7874 (27 July): 232 return to text

Porter, R 1985 'The Patient's View: Doing Medical History from Below', Theory \& Society 14, 2: $175-98$

Post, R 2009 'Debating Disciplinarity’, Critical Inquiry 35, 4: 749-70 return to text

Reverby, SM 2009 Examining Tuskegee: The Infamous Syphilis Study and its Legacy, University of North Carolina Press, Chapel Hill return to text

Rosenhan DL 1973 'On Being Sane in Insane Places', Science 179: 4070: 350-58 return to text

Roskam, J 2013 'Taxpayers Shouldn't Fund Arts Degrees', Australian Financial Review (5 June): http://www.afr.com/Page/Uuid/471671a2-ec4e-11e3-a6b1-29ee4914b70f (accessed 12 December 2014) return to text

Smith, R 1974 'Medical Nemesis’, The Lancet 303, 7867 (8 June): 1160 return to text

Smith, Z 2002 The Autograph Man, Hamish Hamilton, London return to text 
Snow, CP 1959 The Two Cultures and the Scientific Revolution: The Rede Lecture, Cambridge University Press, Cambridge return to text

Thompson, EP 1963 The Making of the English Working Class, Gollancz, London return to text

Weindling, P 2004 Nazi Medicine and the Nuremberg Trials: From Medical War Crimes to Informed Consent, Palgrave Macmillan, Basingstoke return to text

Werskey, G 2007 'The Marxist Critique of Capitalist Science: A History in Three Movements?', Science as Culture 16, 4: 397-461 return to text

White, P 2003 Thomas Huxley: Making the "Man of Science”, Cambridge University Press, Cambridge return to text

James Bradley is Lecturer in the History of Medicine and Life Sciences at the University of Melbourne. He is currently working on a number of projects, including a history of discoveries in the nervous system and a co-authored book with Susan Bradley Smith, Watch Me Die, on the relationship between psychiatry and poetry. He has become increasingly interested in the historical emergence of the biopsychosocial model of medicine, which forms a backdrop to this essay.

Susan Bradley Smith is an award-winning writer and bibliotherapist, and Honorary Research Fellow in English at La Trobe University. Recent publications include Friday Forever, the writing and wellbeing memoir, and the poetry collections Beds For All Who Come (shortlisted for the Victorian Premier's Literary Awards 2015) and Supermodernprayerbook. She is the founder and Creative Director of Milkwood Bibliotherapy, and is currently coauthoring a history of psychiatry and poetry, Watch Me Die, with James Bradley.

\section{TEXT}

Vol 19 No 1 April 2015 http://www.textjournal.com.au General Editor: Nigel Krauth. Editors: Enza Gandolfo \& Linda Weste text@textjournal.com.au 